\title{
Fluoroalkylsilane versus Alkylsilane as Hydrophobic Agents for Silica and Silicates
}

\author{
Damian Ambrożewicz, ${ }^{1}$ Filip Ciesielczyk, ${ }^{1}$ Magdalena Nowacka, ${ }^{1}$ Joanna Karasiewicz, ${ }^{2}$ \\ Adam Piasecki, ${ }^{3}$ Hieronim Maciejewski, ${ }^{2,4}$ and Teofil Jesionowski ${ }^{1}$ \\ ${ }^{1}$ Institute of Chemical Technology and Engineering, Faculty of Chemical Technology, Poznan University of Technology, \\ M. Sklodowskiej-Curie 2, 60965 Poznan, Poland \\ ${ }^{2}$ Department of Organometallic Chemistry, Faculty of Chemistry, Adam Mickiewicz University, Grunwaldzka 6, 60780 Poznan, Poland \\ ${ }^{3}$ Institute of Materials Science and Engineering, Faculty of Mechanical Engineering and Management, Poznan University of Technology, \\ Jana Pawla II 24, 60965 Poznan, Poland \\ ${ }^{4}$ Poznan Science \& Technology Park, AMU Foundation, Rubiez 46, 61612 Poznan, Poland
}

Correspondence should be addressed to Teofil Jesionowski; teofil.jesionowski@put.poznan.pl

Received 3 July 2013; Revised 23 August 2013; Accepted 28 August 2013

Academic Editor: Mengnan Qu

Copyright (C) 2013 Damian Ambrożewicz et al. This is an open access article distributed under the Creative Commons Attribution License, which permits unrestricted use, distribution, and reproduction in any medium, provided the original work is properly cited.

\begin{abstract}
Hydrophobic powders were obtained via surface modification of silica or magnesium silicate with selected silanes. A modified precipitation method, carried out in an emulsion system, was used for monodisperse silica synthesis, while magnesium silicate was precipitated in a traditional water system. Functionalization of the obtained inorganic supports was performed with selected alkylsilanes: one newly synthesized, 3-(2,2,3,3,4,4,5,5-octafluoropentyloxy)propyltriethoxysilane (OPF), and two commercial, octadecylsilane (ODS) and octyltriethoxysilane $\mathrm{C}_{14} \mathrm{H}_{32} \mathrm{O}_{3} \mathrm{Si}(\mathrm{OCS})$, in amounts of 3, 5, or 10 weight parts by mass of $\mathrm{SiO}_{2}$. It was determined how the chemical modification of the silica or magnesium silicate surface affected its physicochemical properties. The dispersive characteristics of both unmodified and functionalized silica-based systems were evaluated. The morphology and microstructure of the samples obtained were analyzed using scanning electron microscopy. The parameters of porous structure of the prepared systems were evaluated on the basis of BET equation as well as nitrogen adsorption/desorption isotherms. Wettability tests as well as elemental analysis of the obtained inorganic oxide hybrids were also performed. In order to verify the effectiveness of silica and magnesium silicate surface functionalization with selected silanes, FTIR spectra were investigated. The resulting experimental data allowed calculation of the degree of coverage of the silica-based systems with modifying agents.
\end{abstract}

\section{Introduction}

Many methods for chemical surface modification of silica and silicate fillers have been proposed. The selection of a specific method depends on the scale of the process (laboratory, industrial), the thickness of the target layer, and the degree of modification [1].

Since the activity of silica fillers depends mainly on their structure, much attention has been paid to the chemical character of surface and possibilities of its modification. An important problem is the modification of their surface by chemical reactions. First of all, the surface of silica and silicate is modified to improve their affinity to organic compounds, polymers in particular. This can be achieved by reduction of surface hydrophilicity and its energy as well as by the introduction of appropriate functional groups [2].

Many methods have been proposed to perform the surface modification of fillers, including the sol-gel method (in which organofunctional groups are introduced onto, e.g., silica during its synthesis) $[3,4]$, a method based on the use of water solvents (modification is carried out in a polar environment of water-methanol or water-acetone type) [5], a method based on the use of organic solvents (carried out in anhydrous conditions, anhydrous organic solvent, and dehydrated surface, and the stage of silane hydrolysis being omitted) [6-10], the method of self-organized monolayers (a variation of adsorption from liquid phase) [11-13], the intermediate hybrid method (developed by Sandoval et 


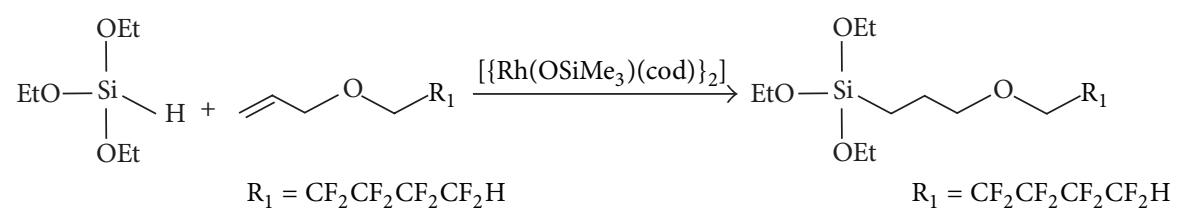

FIGURE 1: Synthesis of 3-(2,2,3,3,4,4,5,5-octafluoropentyloxy)propyltriethoxysilane.

al., employing a two-stage silanization-alkylation procedure instead of alkylsilylation) [14-16], and the gas phase method (fluidal bed) [17-19].

Modification is a complex process depending on many parameters, including the type of solvent, the type and concentration of modifying substance, $\mathrm{pH}$, duration, and the catalysts used. The process involving surface wetting of the substrate is performed in a reactor that should ensure minimum consumption of the modifying agent (the solvent) and the modifier (the proadhesive compound). In the process, the silane coupling agents are attached to the functional silanol groups of the powder substance via the mechanism of electrophilic substitution [20-24].

An addition of a small amount of an organofunctional silane to a certain filler significantly improves its binding ability with organic and/or bioorganic compounds and thus improves the physicochemical properties of final polymer products. Apart from the above application, silane coupling agents are used to enable bonding of metal complexes (catalysis) or enzymes (biochemistry) and to permit the separation of mixtures of hydrocarbons (chromatography).

In the process of modification, organofunctional silanes are deposited from a solution, emulsion, or water suspension. In water media, two processes take place: hydrolysis and condensation. The rate of hydrolysis depends on the concentration of silane, the $\mathrm{pH}$ of the solution $(\mathrm{pH}>10$ and $\mathrm{pH}<5$ give a high rate, $\mathrm{pH}$ near 7 gives the slowest rate), and the character of the functional groups of silanes and alkoxy groups [20-22]. Hydrolysis is catalyzed by hydronium ions $\mathrm{H}_{3} \mathrm{O}^{+}$, hydroxyl ions $\mathrm{OH}^{-}$, Lewis bases, and some metals. Hydrolysis is followed by silane condensation, which is slowest at a $\mathrm{pH}$ of $4-5$, so this is the optimum $\mathrm{pH}$ of the reaction environment, ensuring fast hydrolysis and slow condensation.

Surfactants (anionic, cationic, and non-ionic) [24-29] and proadhesive compounds (silanes: titanates, borates, phosphates, zirconates, and hafnates) [30-36] are commonly used modifiers. Modification significantly extends the range of application of a given silica-based filler. Modified silicates with reduced wettability are used in the construction of sunlight collectors, elements of touch panels for optical and other devices used in industry, and motor vehicles and household utensils and also in the production of new types of textile products $[37,38]$.

The aim of this study was to obtain silica-based systems characterized by well-defined physicochemical properties including high degree of dispersion and high hydrophobicity, by means of surface functionalization with selected alkylsilanes.

\section{Experimental}

2.1. Materials. Highly dispersed silica was obtained in a process of precipitation, carried out in an emulsion system, using $5 \%$ solutions of sodium silicate $\left(\mathrm{Na}_{2} \mathrm{O} 8.50 \%, \mathrm{SiO}_{2}\right.$ $27.18 \%$, density $1.39 \mathrm{~g} / \mathrm{cm}^{3}$, modulus 3.3 , Vitrosilicon $\mathrm{SA}$ ) and hydrochloric acid (analytical grade, density $1.19 \mathrm{~g} / \mathrm{cm}^{3}$, POCh SA) as the initial substrates. Cyclohexane (analytical grade, density $0.779 \mathrm{~g} / \mathrm{cm}^{3}$, POCh SA) as the organic phase and nonylphenylpolyoxyethyleneglycol ethers NP3 and NP6 $\left(\mathrm{C}_{9} \mathrm{H}_{19} \mathrm{Ph}\left(\mathrm{CH}_{2} \mathrm{CH}_{2} \mathrm{O}\right)_{n} \mathrm{H}\right.$, purchased from Sigma-Aldrich) as emulsifying agents determining the stability of the emulsion were also used.

On the other hand, magnesium silicate was precipitated from $5 \%$ aqueous solutions of sodium silicate and magnesium sulfate $\left(\mathrm{MgSO}_{4} \cdot 7 \mathrm{H}_{2} \mathrm{O}\right.$, analytical grade, density $2.66 \mathrm{~g} / \mathrm{dm}^{3}$, purchased from Chempur).

The surface of those inorganic supports was grafted with selected silanes: one newly synthesized, 3-(2,2,3,3,4,4,5,5octafluoropentyloxy)propyl-triethoxysilane $\mathrm{C}_{14} \mathrm{H}_{24} \mathrm{~F}_{8} \mathrm{O}_{4} \mathrm{Si}$ (OPF), and two commercial, octadecylsilane $\mathrm{C}_{18} \mathrm{H}_{40} \mathrm{Si}$ (ODS) and octyltriethoxysilane $\mathrm{C}_{14} \mathrm{H}_{32} \mathrm{O}_{3} \mathrm{Si}$ (OCS), both with $97 \%$ purity, purchased from Sigma-Aldrich (Table 1).

2.1.1. Synthesis of Fluorocarbofunctional Triethoxysilane $(O P F)$. Synthesis of OPF was carried out in a two-stage process. In the first stage, allyl-fluoroalkyl ether was obtained via the Williamson reaction, using fluoroalkyl alcohol and allyl chloride. Then the allyl-fluoroalkyl ether was subjected to hydrosilylation with triethoxysilane in the presence of siloxide rhodium complex as catalyst [39] (Figure 1).

$1,1,2,2,3,3,4,4$-octafluoropentyl allyl ether in a quantity of $20.4 \mathrm{~g}(75 \mathrm{mmol})$ and rhodium catalyst in a quantity of $0.22 \mu \mathrm{g}\left(10^{-5} \mathrm{~mol} \mathrm{Rh} / 1 \mathrm{~mol} \equiv \mathrm{Si}-\mathrm{H}\right) \quad\left[\left\{\mathrm{Rh}\left(\mathrm{OSiMe}_{3}\right)(\mathrm{cod})\right\}_{2}\right]$ were placed in a three-neck round-bottom flask equipped with a thermometer, condenser, and magnetic bar. Then $11.5 \mathrm{~g}$ of triethoxysilane $(70 \mathrm{mmol})$ was introduced, and the solution was heated up to $60^{\circ} \mathrm{C}$ and kept at that temperature for $1 \mathrm{~h}$. After the reaction was completed, the solvent and excess of olefin were evaporated under vacuum to give the product in a quantity of $29.9 \mathrm{~g}$ ( $98 \%$ of the theoretical yield).

The product structure was confirmed by NMR analysis.

${ }^{1} \mathrm{H} \quad \mathrm{NMR} . \quad\left(\mathrm{C}_{6} \mathrm{D}_{6}, \quad 298 \mathrm{~K}, \quad 300 \mathrm{MHz}\right) \quad \delta \quad(\mathrm{ppm}): 0.6$ $\left(2 \mathrm{H}, \quad-\mathrm{SiCH}_{2}-\right) ; 1.13\left(9 \mathrm{H}, \mathrm{CH}_{3}-\right) ; 1.67 \quad\left(2 \mathrm{H},-\mathrm{CH}_{2}-\right)$; $3.17\left(2 \mathrm{H},-\mathrm{CH}_{2} \mathrm{O}-\right) ; 3.47\left(2 \mathrm{H}, \quad-\mathrm{OCH}_{2}-\mathrm{CF}_{2}-\right) ; 3.72$ $\left(6 \mathrm{H}, \mathrm{CH}_{3}-\mathrm{CH}_{2} \mathrm{O}-\right) ; 5.59\left(1 \mathrm{H},-\mathrm{CF}_{2} \mathrm{H}\right)$.

${ }^{13}$ C NMR. $\left(\mathrm{C}_{6} \mathrm{D}_{6}, 298 \mathrm{~K}, 75.5 \mathrm{MHz}\right) \delta(\mathrm{ppm}): 6.73\left(-\mathrm{SiCH}_{2}-\right)$; $18.38\left(-\mathrm{CH}_{3}\right) ; 23.34\left(-\mathrm{CH}_{2}-\right) ; 58.47\left(-\mathrm{OCH}_{2} \mathrm{CH}_{3}\right) ; 67.52$ 
TAble 1: Alkylsilanes' characteristics.

$\begin{array}{lll}\text { Name } & \text { Acronym } & \begin{array}{c}\text { Chemical } \\ \text { formula }\end{array} \\ \begin{array}{l}\text { 3-(2,2,3,3,4,4,5,5- } \\ \text { octafluoropentyloxy)propyl- } \\ \text { triethoxysilane }\end{array} & \mathrm{OPF} & \mathrm{ODS}\end{array}$

$\left(-\mathrm{OCH}_{2} \mathrm{CF}_{2}-\right) ; 75.03 \quad\left(-\mathrm{CH}_{2} \mathrm{O}-\right) ; 108.17,111.53,116.00$ $\left(-\mathrm{CF}_{2}-\right) ; 119.39\left(-\mathrm{CF}_{2} \mathrm{H}\right)$.

${ }^{29} \mathrm{Si} N M R . \quad\left(\mathrm{C}_{6} \mathrm{D}_{6}, 298 \mathrm{~K}, 59.6 \mathrm{MHz}\right) \delta(\mathrm{ppm}):-46.14$ $\left((\mathrm{EtO})_{3} \mathrm{SiCH}_{2}-\right)$.

\subsection{Procedures and Methods}

2.2.1. Precipitation of Silica. Precipitation of the silica support took place in a two-emulsion system. The first emulsion, E1, was formed using $5 \%$ solution of sodium silicate (as silica precursor), cyclohexane (as organic phase), and nonionic surfactants NP3 and NP6 in quantities of $2.3 \mathrm{~g}$ and $2.5 \mathrm{~g}$, respectively (as emulsifiers). Emulsion E2 was formed with a $5 \%$ solution of hydrochloric acid, cyclohexane, and a mixture of the same emulsifiers but in quantities of $1.5 \mathrm{~g}$ and $1.3 \mathrm{~g}$, respectively. Before the precipitation process, emulsion E2 was placed in a special reactor equipped with a high-speed homogenizer, to which homogenized E1 was added at a constant rate of $10 \mathrm{~cm}^{3} / \mathrm{min}$. As a result of the reaction, an emulsion containing silica was obtained. Then the reaction system was heated up to $80^{\circ} \mathrm{C}$, in order to destabilize the emulsion, and after that it was possible to separate the organic phase using a vacuum evaporator made by Büchi Labortechnik GmbH. The mixture was filtered off under reduced pressure and the filtrate was washed with hot water and then with acetone in order to remove surfactant residues. Finally, the sample was dried by a convection method at $105^{\circ} \mathrm{C}$ for $48 \mathrm{~h}$, using a MEMMERT dryer.

2.2.2. Precipitation of Magnesium Silicate. Highly dispersed magnesium silicate was precipitated in a reactor of $10 \mathrm{dm}^{3}$ in capacity (made by QVF MiniPlant PILO-TEC) equipped with a high-speed stirrer $(1000 \mathrm{rpm})$. The precipitation reaction was carried out at room temperature. At the beginning of the process, a certain volume of a 5\% solution of magnesium silicate was placed in the reactor, to which a $5 \%$ solution of sodium silicate was introduced using a peristaltic pump at a constant rate of $20 \mathrm{~cm}^{3} / \mathrm{min}$. The process lasted for about $5 \mathrm{~h}$.

The precipitate was separated from the postreaction mixture by filtration, and then the filtrate was washed a few times with hot, distilled water to remove residues of unreacted salts. Then the samples were dried at $105^{\circ} \mathrm{C}$ and classified.

The silica and the magnesium silicate obtained were subjected to a comprehensive range of tests to evaluate their physicochemical properties.

\subsubsection{Surface Modification of Silica and Magnesium Silicate} by Chemical Method. The inorganic powders obtained were subjected to surface modification with selected silanes (see Table 1) used in quantities of 3, 5, and 10 weight parts by mass of $\mathrm{SiO}_{2}$. Modifying agents were first hydrolyzed in a methanol/water system $(4 / 1, \mathrm{v} / \mathrm{v})$ with a controlled $\mathrm{pH}$ value being maintained in the range of 4-5. After that, the modifying mixture was sprayed onto the surface of the filler. Modification was performed using a vacuum evaporator, to which the mixture of obtained silica or silicate together with the modifying agent was introduced. In this way, it was possible to remove the organic solvent (methanol) from the reaction mixture. The process lasted for 1 hour.

2.2.4. Physicochemical Properties of the Obtained Hybrids. The dispersive characteristics (particle size distributions) of the fillers obtained were evaluated with a Zetasizer Nano 
ZS and a Mastersizer 2000, both made by Malvern Instruments Ltd., using the noninvasive backscattering (NIBS) method and laser diffraction technique, respectively. These two devices enable the measurement of particle sizes in different ranges: $0.6-6000 \mathrm{~nm}$ and $0.2-2000 \mu \mathrm{m}$, respectively. Mastersizer 2000 allowed to obtained characteristic dispersion parameters such as $d(0.1), d(0.5), d(0.9)$, and $D[4.3]$. The terms $d(0.1), d(0.5)$, and $d(0.9)$ correspond, respectively, to the frequencies of $10 \%, 50 \%$, and $90 \%$. For instance, $d(0.5)$ means that $50 \%$ of the particles possess a diameter less than a given value. Thus, the term $D[4.3]$ is described as mean particle diameter calculated form the whole sample volume. The morphology and microstructure of the samples were determined using a scanning electron microscope (Zeiss EVO40). The observations permitted evaluation of the degree of dispersion, the structure of particles, and the nature of agglomerations. The effectiveness of the functionalization process was also evaluated on the basis of zeta potential measurements. Zeta potential was measured by the electrophoretic light scattering method using a Zetasizer Nano ZS instrument equipped with an autotitrator made by Malvern Instruments Ltd. The electrokinetic potential was measured in the presence of a $0.001 \mathrm{M} \mathrm{NaCl}$ electrolyte. Measurements were performed in the $\mathrm{pH}$ range from 1.5 to 11 , which enabled the determination of the electrokinetic curves. The standard deviation of the zeta potential at a given $\mathrm{pH}$ was $\pm 1.5 \mathrm{mV}$ or less, and the error in the $\mathrm{pH}$ was estimated to be $0.05 \mathrm{pH}$ units or lower. The degree of modification of the inorganic supports with selected alkylsilanes was determined using a FTIR EQUINOX 55 spectrophotometer made by Bruker. The obtained fillers were subjected to FTIR analysis after tabletting using $\mathrm{KBr}$. The chemical composition of the modified fillers was determined using a Vario EL Cube apparatus made by Elementar Analysensysteme GmbH and using a Specs Phoibos-100 spectrophotometer operating based on the XPS (X-ray photoelectron spectroscopy) method. Parameters of porous structure (surface area and pore size distribution) were also evaluated for selected samples. Measurements were made using an ASAP 2020 instrument made by Micromeritics Instrument Co. operating on the basis of low-temperature nitrogen adsorption.

In order to characterize the hydrophilic/hydrophobic character of the obtained fillers, they were subjected to wettability tests, performed by the sorption method using a K100 tensiometer (Krüss). Measurements were performed for about $600 \mathrm{~s}$, until the sample attained a constant mass.

\section{Results and Discussion}

In the first stage of the research, a comparative analysis was carried out on the dispersive and morphological properties (SEM observations) of unmodified silica and $\mathrm{SiO}_{2}$ functionalized with 5 weight parts by mass of $3-(2,2,3,3,4,4,5,5-$ octafluoropentyloxy)propyltriethoxysilane (OPF), octadecylsilane (ODS), and octyltriethoxysilane (OCS) (Figures 2 and 3 ).
Figure 2 presents the particle size distributions, according to volume contribution, determined for both unmodified and silica modified with 5 weight parts by mass of OPF (Figure 2(b)), ODS (Figure 2(c)), or OCS (Figure 2(d)). Monodisperse particle size distribution was obtained only for unmodified silica, and the dominant volume contribution of $38.3 \%$ was recorded for particles of $531 \mathrm{~nm}$ in diameter. Modification of the silica surface resulted in an increase in the particles' tendency to agglomerate (presence of secondary agglomerates). The sample modified with 5 weight parts by mass of ODS is characterized by bimodal particle size distribution; the two bands correspond to particle diameters in the range of 91-295 $\mathrm{nm}$ and $1480-6440 \mathrm{~nm}$, respectively. Similarly, the particle size distribution of the sample modified with 5 weight parts by mass of OPF is also bimodal, with the two bands covering the particle diameter ranges of 142$255 \mathrm{~nm}$ and 2670-6440 $\mathrm{nm}$ (Figure 2(b)). The SEM image of unmodified silica (Figure 3(a)) confirms the high homogeneity and spherical shape of the particles, with low tendency towards agglomerate formation, which is also confirmed by the low polydispersity index of 0.289 . The SEM image of silica modified with 5 weight parts by mass of OPF also confirms the presence of spherically shaped particles, but they are less regular and tend to form agglomerates (Figures 3(b)-3(d)). The polydispersity index of this sample is 0.460 .

As follows from the literature [40-42], the alkoxysilanes, especially those containing $=\mathrm{NH}$ or $-\mathrm{NH}_{2}$ groups, have been mostly used for surface modification of emulsion silicas and induce a considerable increase in the tendency towards formation of primary and secondary agglomerates. The SEM images presented in Figures 3(e)-3(f) also confirm that the particles' tendency to form agglomerates in the sample of silica modified with applied silanes is greater than in the unmodified $\mathrm{SiO}_{2}$. Microscopic observations are in agreement with particle size measurement results.

Figure 4 allows a comparison of the particle size distributions obtained for both unmodified and magnesium silicate modified with 5 weight parts by mass of the three different silane coupling agents. Table 2 gives the dispersive characteristics of magnesium silicate-based fillers. As follows from these data, the modification process of $\mathrm{MgO} \cdot \mathrm{SiO}_{2}$ causes small changes in the particle sizes of the obtained fillers. The unmodified magnesium silicate is composed of particles with diameters ranging from 1 to $100 \mu \mathrm{m}$. The dominant volume contribution of $5.01 \%$ is recorded for particles $39.8 \mu \mathrm{m}$ in diameter (Figure 4 and Table 2). Analysis of the results shows that in this sample $10 \%$ of particles have diameters not greater than $3.8 \mu \mathrm{m}, 50 \%$ have diameters not greater than $22.5 \mu \mathrm{m}$, and $90 \%$ have diameters smaller than $73.6 \mu \mathrm{m}$. The mean diameter of particles $D[4.3]$ in the sample of unmodified $\mathrm{MgO} \cdot \mathrm{SiO}_{2}$ is $31.5 \mu \mathrm{m}$. Modification of magnesium silicate with 5 weight parts by mass of OPF, ODS, or OCS resulted in increased particle size. The sample modified with 5 weight parts by mass of OPF contained $10 \%$ of particles with diameters below $8.7 \mu \mathrm{m}, 50 \%$ with diameters not greater than $35.6 \mu \mathrm{m}$, and $90 \%$ with diameters smaller than $94.0 \mu \mathrm{m}$. In turn, the inorganic support modified with 5 weight parts by mass of ODS is characterized by a $10 \%$ volume contribution of particles with diameters below $6.6 \mu \mathrm{m}$, while $50 \%$ have 


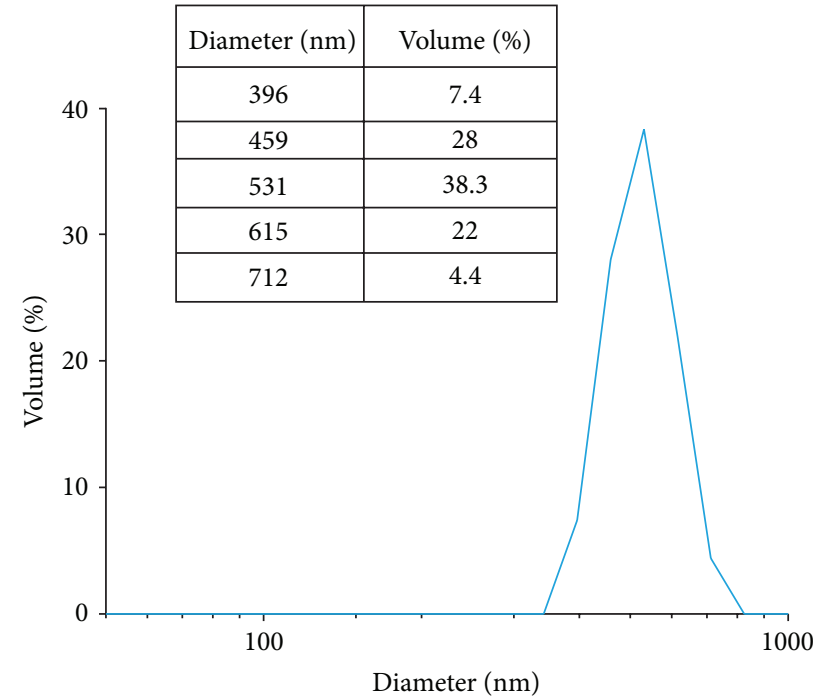

(a)

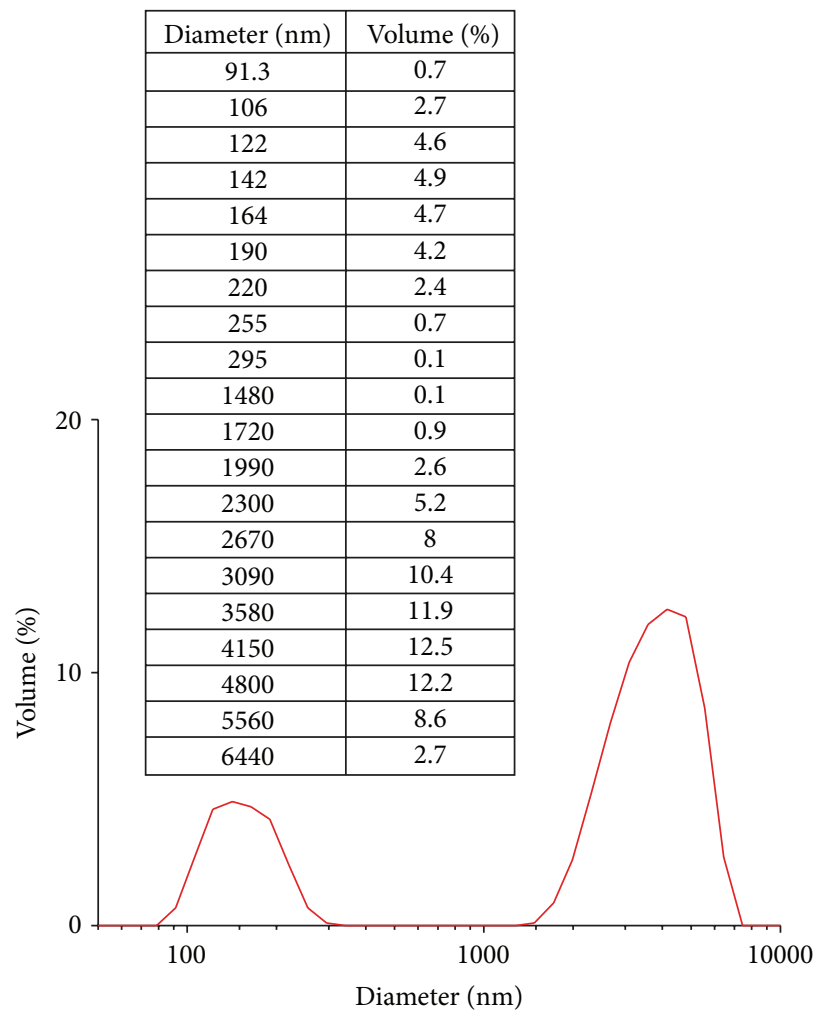

(c)

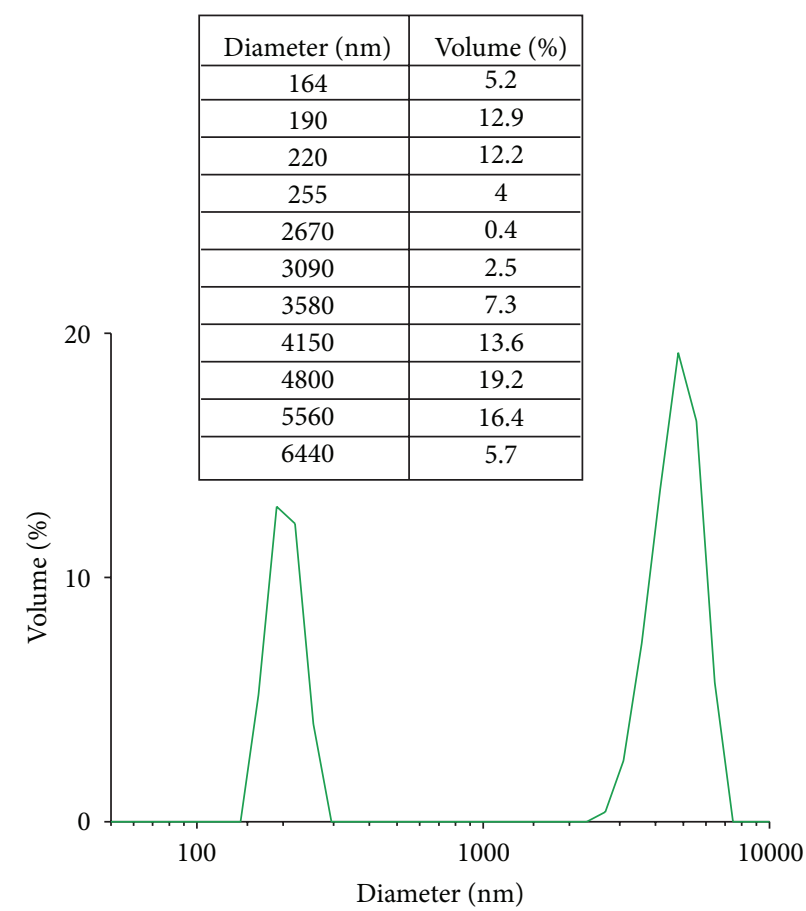

(b)

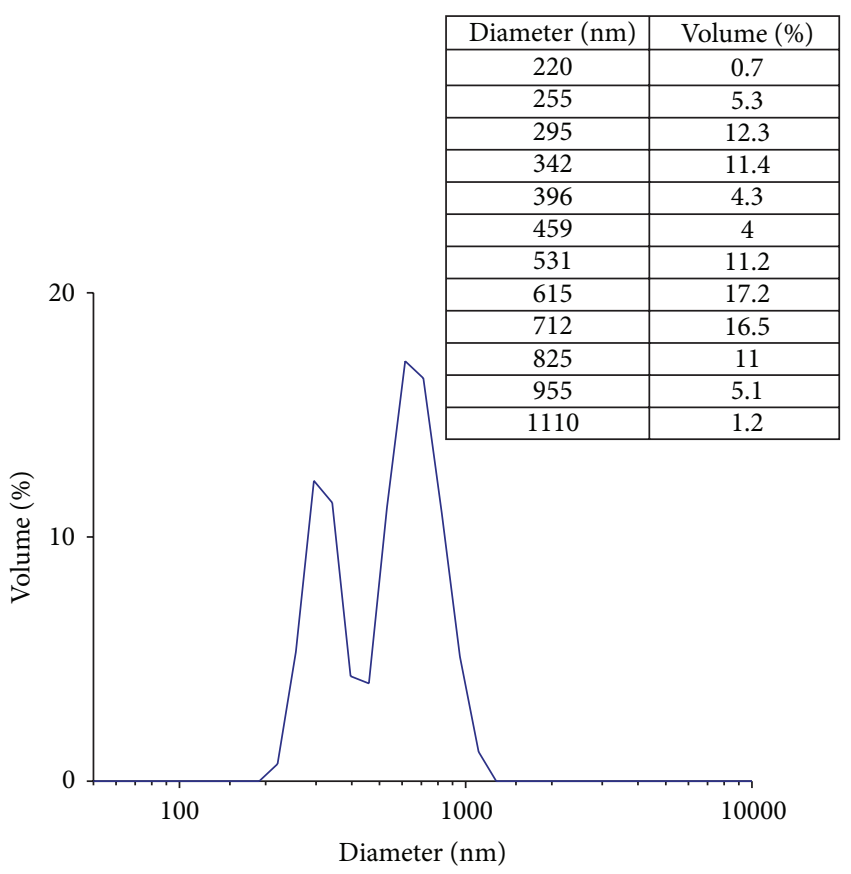

(d)

FIGURE 2: Particle size distributions of unmodified silica (a) and silica modified with 5 weight parts by mass of OPF (b), ODS (c), and OCS (d). 


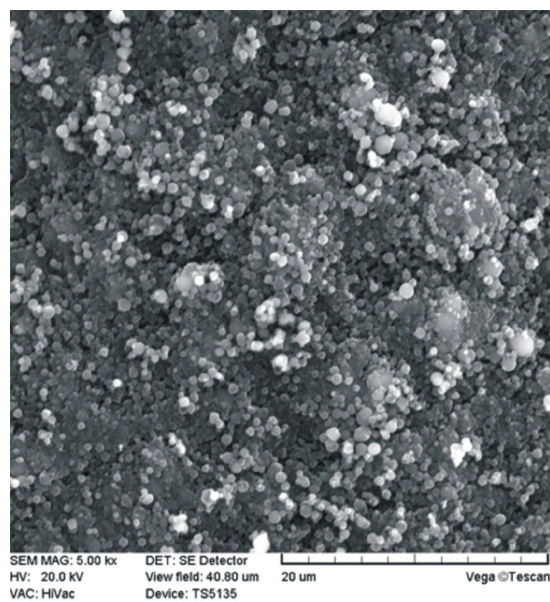

(a)

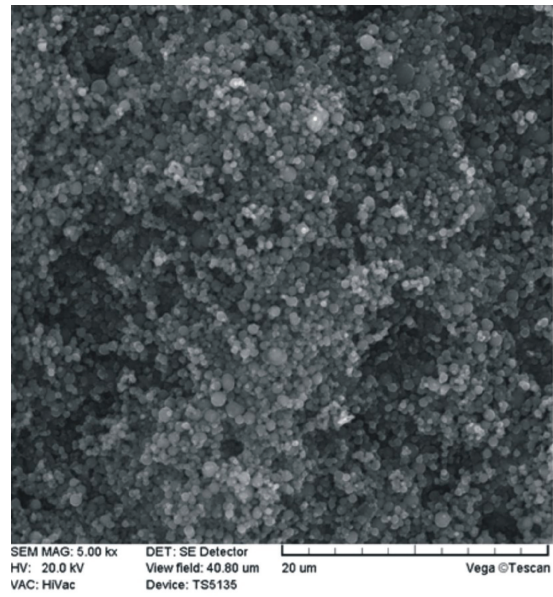

(c)

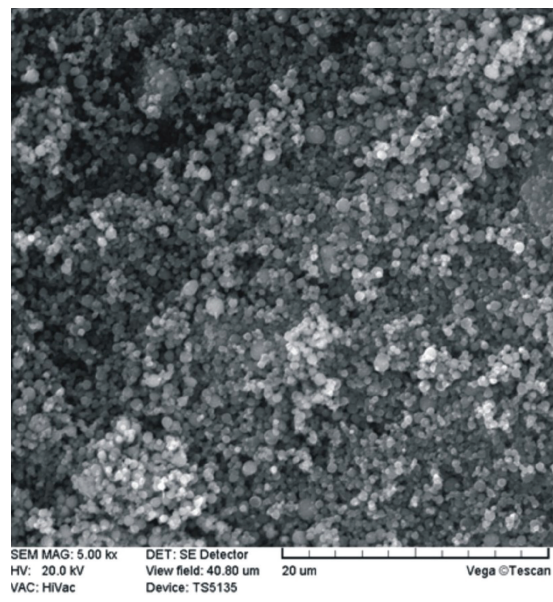

(e)

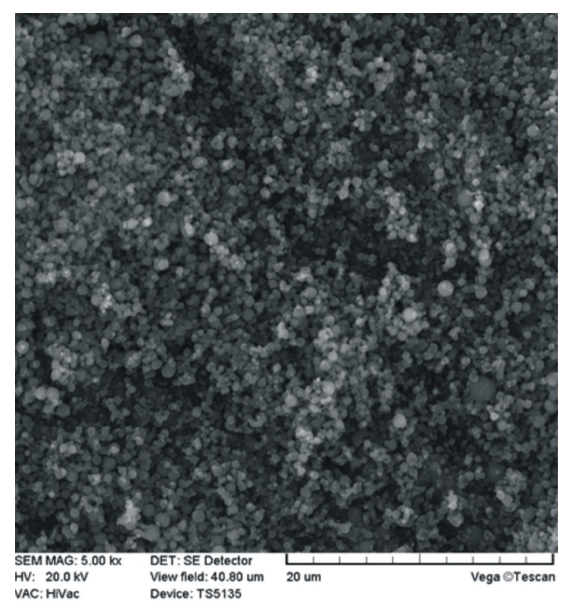

(b)

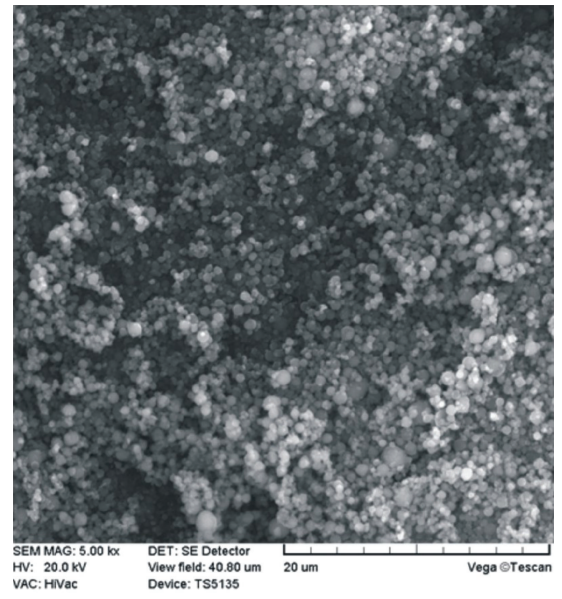

(d)

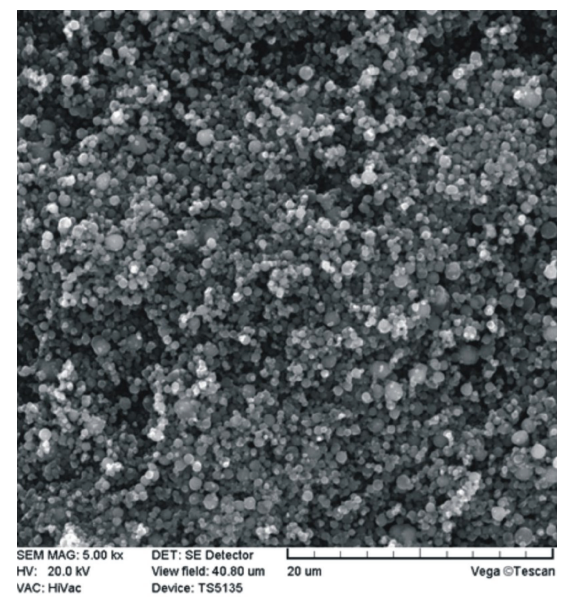

(f)

FigURE 3: SEM images of unmodified silica, (a) silica functionalized with 3, 5, and 10 weight parts by mass of OPF ((b), (c), and (d)), respectively, and 5 weight parts by mass of ODS (e) and OCS (f). 
TABle 2: Dispersive parameters of unmodified $\mathrm{MgO} \cdot \mathrm{SiO}_{2}$ and magnesium silicate modified with different alkylsilanes.

\begin{tabular}{|c|c|c|c|c|}
\hline \multirow{2}{*}{ Sample } & \multicolumn{3}{|c|}{ Diameter $(\mu \mathrm{m})$} & \multirow{2}{*}{ Mean diameter $D(4.3)(\mu \mathrm{m})$} \\
\hline & $d(0.1)$ & $d(0.5)$ & $d(0.9)$ & \\
\hline $\mathrm{MgO} \cdot \mathrm{SiO}_{2}$ & 3.8 & 22.5 & 73.6 & 31.5 \\
\hline $\mathrm{MgO} \cdot \mathrm{SiO}_{2}+5$ weight parts by mass of OPF & 8.7 & 35.6 & 94.0 & 42.0 \\
\hline $\mathrm{MgO} \cdot \mathrm{SiO}_{2}+5$ weight parts by mass of ODS & 6.6 & 30.8 & 91.0 & 46.0 \\
\hline $\mathrm{MgO} \cdot \mathrm{SiO}_{2}+5$ weight parts by mass of OCS & 8.2 & 37.0 & 96.0 & 44.0 \\
\hline
\end{tabular}

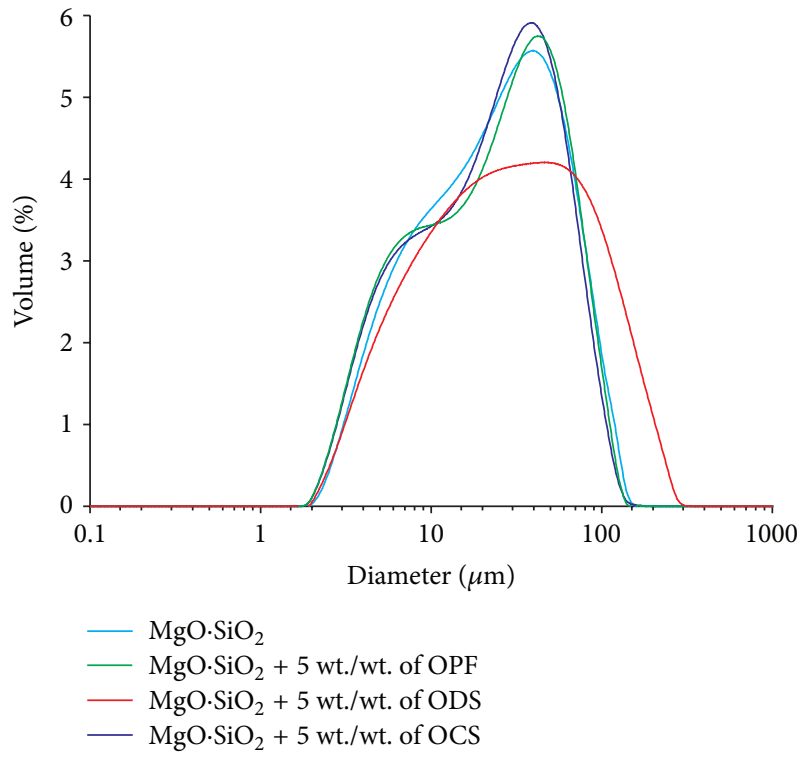

FIGURE 4: Comparison of particle size distributions of unmodified $\mathrm{MgO} \cdot \mathrm{SiO}_{2}$ and magnesium silicate modified with 5 weight parts by mass of different silanes.

diameters below $30.8 \mu \mathrm{m}$ and $90 \%$ have diameters below $91.0 \mu \mathrm{m}$. Moreover, the dispersive parameters $d(0.1)=8.2 \mu \mathrm{m}$, $d(0.5)=37.0 \mu \mathrm{m}$, and $d(0.9)=96.0 \mu \mathrm{m}$ are found for the magnesium silicate sample modified with 5 weight parts by mass of OCS. The particle diameter ranges are confirmed by the SEM images presented in Figure 5.

Figure 6(a) presents a comparison of the dependencies of zeta potential on $\mathrm{pH}$ for unmodified silica and for the samples modified with 5 weight parts by mass of selected silanes. Modification with silanes leads to the introduction of new chemical groups on the silica surface, which changes its initial properties and also the surface charge, manifested by the values of zeta potential.

Electrokinetic potential of unmodified silica is negative in the entire $\mathrm{pH}$ range studied and the isoelectric point (IEP) was reached at $\mathrm{pH}$ close to 1.7. The unmodified silica is characterized by high electrokinetic stability for $\mathrm{pH}$ values ranging from 4 to 11 , which is manifested by zeta potential values from $-30 \mathrm{mV}$ to $-52 \mathrm{mV}$. The most pronounced changes in the electrokinetic properties were noted as a result of silica modification with 5 weight parts by mass of OPF, while the changes caused by modification with 5 weight parts by mass of OCS and ODS with respect to the curve obtained for the unmodified silica sample were insignificant. Modification of the $\mathrm{SiO}_{2}$ surface with OPF results in a significant shift of the electrokinetic curve towards higher $\mathrm{pH}$, relative to that for the unmodified sample. Sample modified with OPF is stable at $\mathrm{pH}$ from 6 to 11 and its zeta potential values vary from -2 to $-33 \mathrm{mV}$ over the $\mathrm{pH}$ range analyzed.

The character of electrokinetic curves is an indirect confirmation of the effectiveness of the proposed method of surface modification.

In the case of magnesium silicate grafted with different silanes, changes in the electrokinetic properties was not much significant. Magnesium silicate-based samples are characterized with zeta potential range of $10-(-48) \mathrm{mV}$. In the $\mathrm{pH}$ range of 3-12 all samples have negative zeta potential values with the highest negative value of $-48 \mathrm{mV}$ obtained for the sample modified with 5 weight parts by mass of OPF silane. In comparison to the silica-based fillers, all samples of $\mathrm{MgO}$ $\mathrm{SiO}_{2}$ grafted with silanes exhibit IEP (isoelectric point- $\mathrm{pH}$ at which zeta potential is 0 ) which value is determined by its higher base surface character and the surface charge changes caused by modification process. Unmodified magnesium silicate has IEP at $\mathrm{pH}=3$; on the other hand, sample modified with 5 weight parts by mass of ODS $-\mathrm{pH}=3.3$ and samples modified with 5 weight parts by of OPF and OCS $-\mathrm{pH}=3.6$.

The effectiveness and chemical nature of the modification process were evaluated on the basis of FTIR spectra. Figure 7(a) shows the FTIR spectra of raw silica and $\mathrm{SiO}_{2}$ functionalized with 5 weight parts by mass of three different alkylsilanes. The FTIR spectra show common bands assigned to various vibrations in the solid network. The analysis of those spectra revealed the broad band centered at around $3470-3450 \mathrm{~cm}^{-1}$ which corresponds to the overlapping of the -OH stretching bands of hydrogen-bonded water molecules as well as $\mathrm{Si}-\mathrm{OH}$ stretching of surface silanols hydrogenbonded to molecular water. Furthermore, the Si-O in-plane stretching vibrations of the silanol $\mathrm{Si}-\mathrm{OH}$ groups appear at around $960 \mathrm{~cm}^{-1}$, and the absorption bands corresponding to the adsorbed water molecules deformation vibrations appear at $1653-1634 \mathrm{~cm}^{-1}$ which is in agreement with [43]. The absorption of water molecules on the surface of such powders is due to the existence of the surface silanol groups and therefore to the hydrophilic nature of those materials. The intense silicon-oxygen covalent bonds vibrations appear mainly in the $1200-1000 \mathrm{~cm}^{-1}$ range, revealing the existence of a dense silica network, where oxygen atoms play the role of bridges between each two silicon sites. The very intense and broad band appearing at $1095-1089 \mathrm{~cm}^{-1}$ and the shoulder at around $1200 \mathrm{~cm}^{-1}$ are assigned, respectively, to the transversal optical and longitudinal optical modes of the $\mathrm{Si}-\mathrm{O}-\mathrm{Si}$ asymmetric 


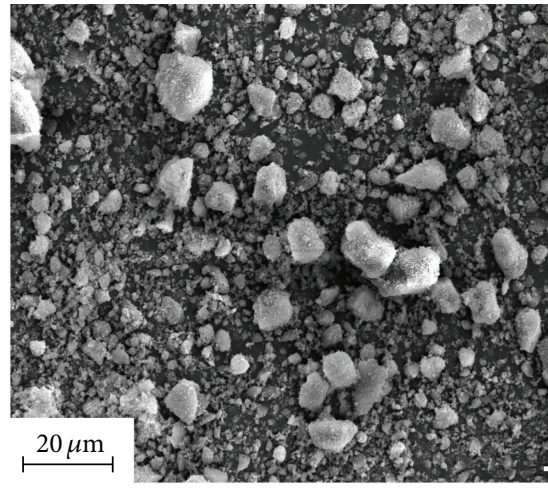

(a)

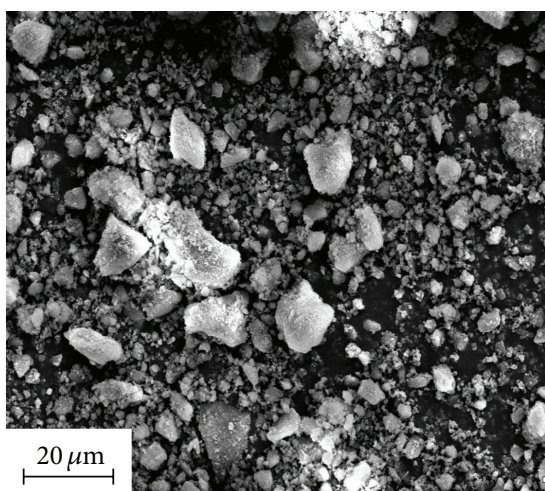

(c)

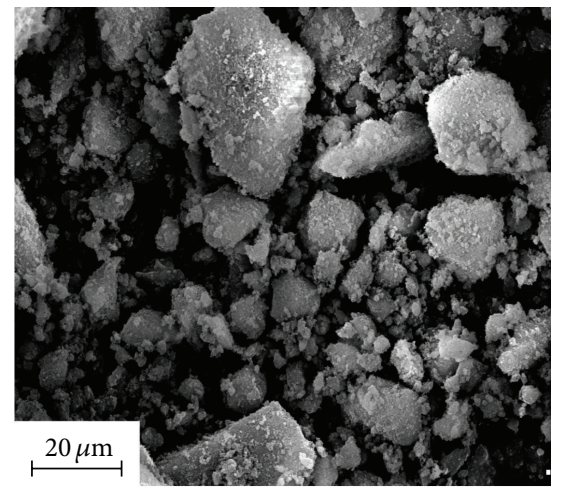

(b)

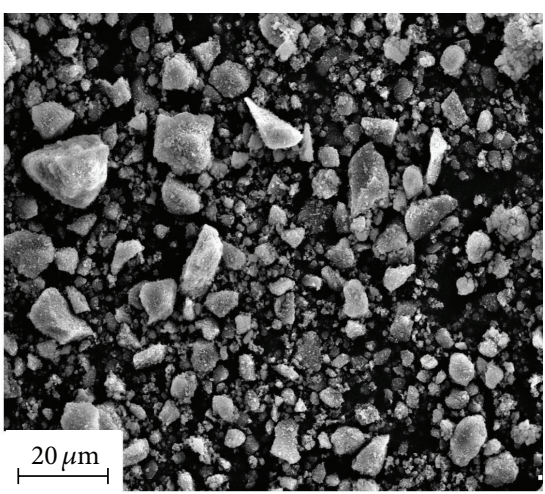

(d)

FIGURE 5: SEM images of unmodified magnesium silicate (a) and $\mathrm{MgO} \cdot \mathrm{SiO}_{2}$ modified with 5 weight parts by mass of OPF (b), ODS (c), and OCS (d).

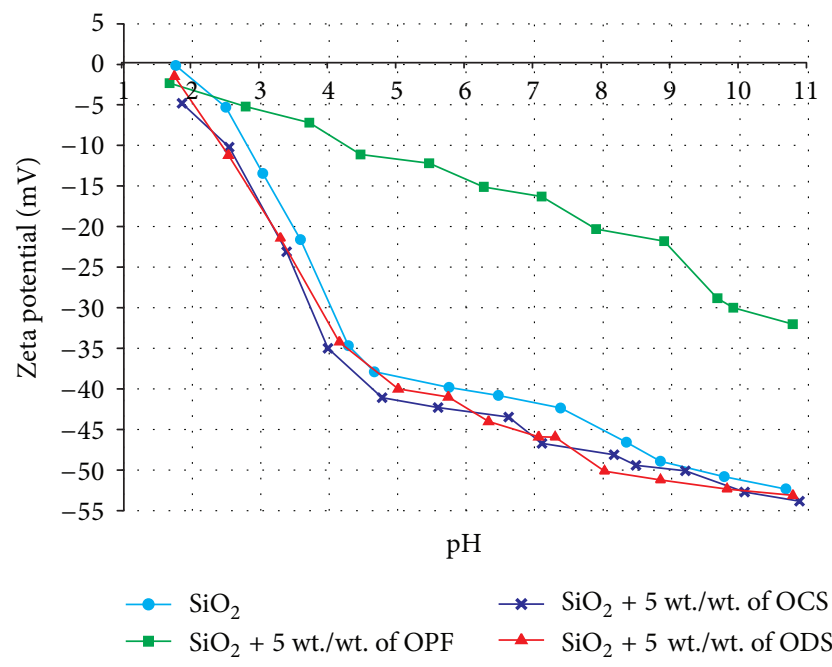

(a)

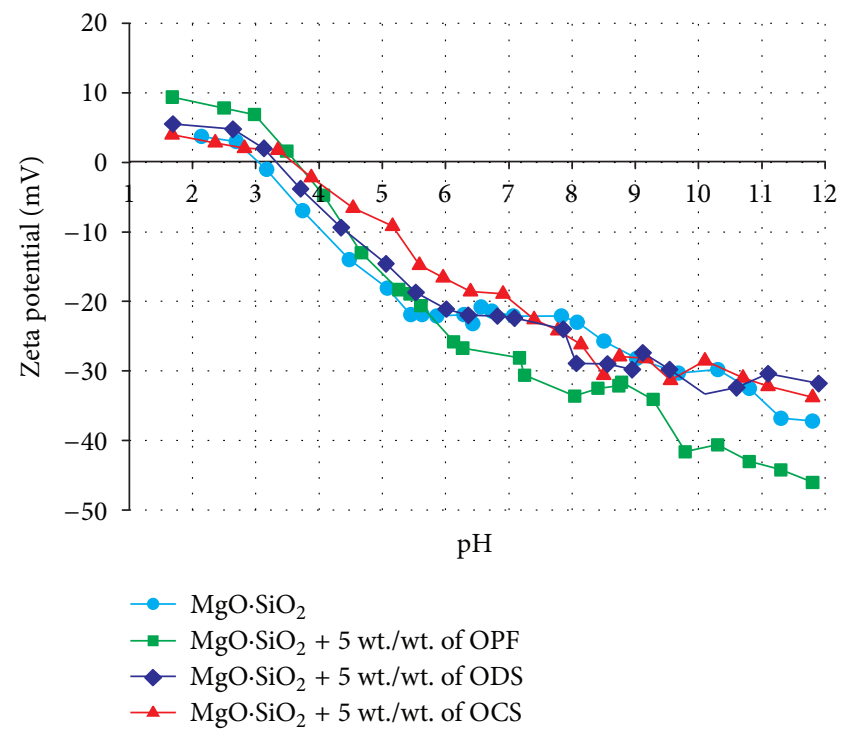

(b)

FIgURE 6: Zeta potential versus $\mathrm{pH}$ for $\mathrm{SiO}_{2}$ (a) and magnesium silicate (b) grafted with 5 weight parts by mass of tested silanes. 


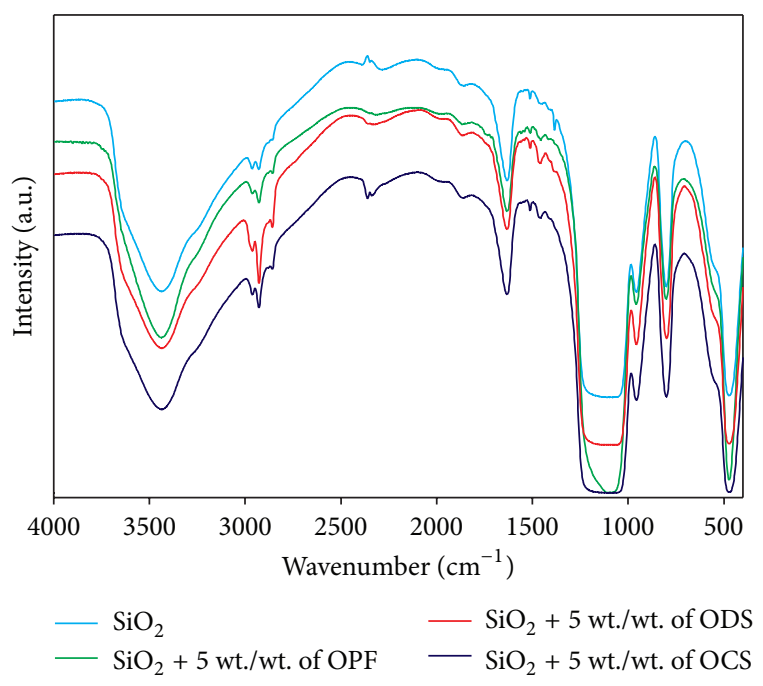

(a)

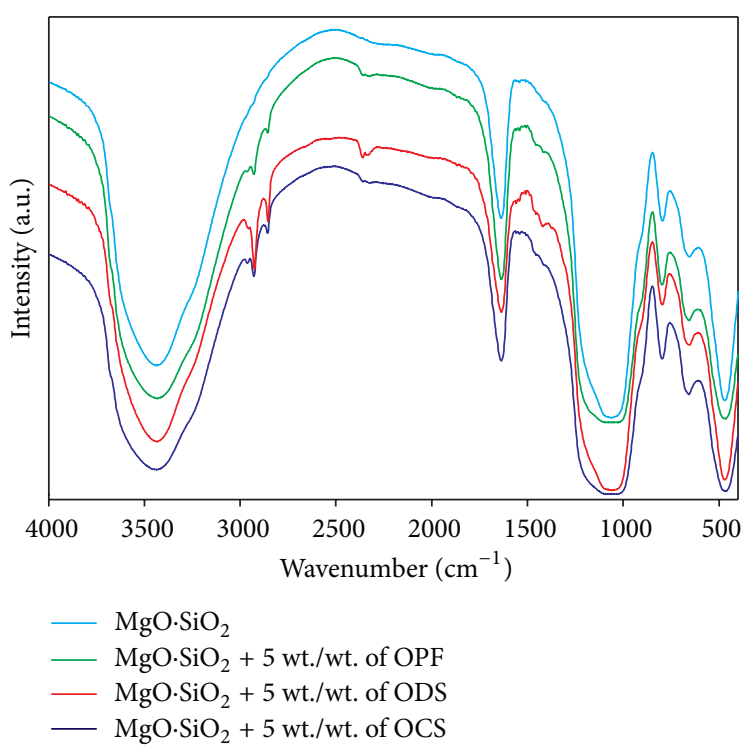

(b)

FIGURE 7: Comparison of the FTIR spectra of silica (a) and $\mathrm{MgO} \cdot \mathrm{SiO}_{2}$ (b) modified with 5 weight parts by mass of silanes.

stretching vibrations as also presented in [44]. On the other hand, the symmetric stretching vibrations of $\mathrm{Si}-\mathrm{O}-\mathrm{Si}$ appear at $800 \mathrm{~cm}^{-1}$ and its bending mode appears at $469-467 \mathrm{~cm}^{-1}$ which is in agreement with [43]. The FT-IR spectrum of silica modified with 5 weight parts by mass of OPF shows that the bands attributed to the stretching vibrations of $-\mathrm{CH}$ groups $\left(2965-2850 \mathrm{~cm}^{-1}\right)$ as well as of $-\mathrm{CH}_{3}$ groups become much more intensive. The increase in the intensities of these peaks is coupled to the increase of the intensities of the $\mathrm{C}-\mathrm{H}$ deformation peaks appearing between 1466 and $1379 \mathrm{~cm}^{-1}$. This spectrum also shows peak at $1341 \mathrm{~cm}^{-1}$ that could be assigned to the $-\mathrm{CH}_{2}$ - deformation vibrations of the propyl group. Thus, the spectrum of silica modified with 5 weight parts by mass of OCS shows very intense asymmetric and symmetric C-H stretching vibrations between 2930 and $2858 \mathrm{~cm}^{-1}$. The existence of these intense bands is due to the large number of $-\mathrm{CH}_{2}$ groups in the octyl-modified silica material, showing their rocking vibrations at $723 \mathrm{~cm}^{-1}$. The existence of these octyl-surface groups is coupled with an increase of the hydrophobicity of the samples shown by the decrease of the intensities of the surface-absorbed water at 3450 and $1635 \mathrm{~cm}^{-1}$. FT-IR spectrum for sample modified with 5 weight parts by mass of ODS shows an increase in the intensities of the $\mathrm{CH}_{3}$ (from $\left.\nu(\mathrm{C}-\mathrm{H})\right) 2956 \mathrm{~cm}^{-1},-\mathrm{CH}_{2}$ 2913 and $2848 \mathrm{~cm}^{-1}$, and $\mathrm{C}-\mathrm{H}$ deformation peaks appearing between 1466 and $1379 \mathrm{~cm}^{-1}$. The spectra showed peaks at $1341 \mathrm{~cm}^{-1}$ that could be assigned to the $-\mathrm{CH}_{2}-$ deformation vibrations of the silane group which is in agreement with $[45,46]$.

Figure 7 shows IR spectra of unmodified silicate and powder modified with 5 weight parts by mass of different silanes. The FTIR spectra confirm the hydrophilic surface character of the magnesium silicate result from the process of its precipitation in a polar medium. They show a clear character with the principal $\mathrm{Si}-\mathrm{O}$ stretching bands at 1000 $1080 \mathrm{~cm}^{-1}$, a Si-OH deformation band at $895 \mathrm{~cm}^{-1}$, a single $\mathrm{Si}-\mathrm{O}-\mathrm{Mg}$ bending vibration at $450 \mathrm{~cm}^{-1}$ (with a shoulder at $400 \mathrm{~cm}^{-1}$ ), and perpendicular $\mathrm{Mg}$ vibrations at $555 \mathrm{~cm}^{-1}$, which is in agreement with $[47,48]$. The absorption band covering the range of $3850-3150 \mathrm{~cm}^{-1}$ is attributed to water adsorbed on the surface of silicate, the same as in the case of silica (Figure 7(a)). Modification of magnesium silicate with different silanes results in the same changes in the FTIR spectra and presence of the same groups characteristic for modifier molecules as compared to silica spectra, but less intensive.

The effectiveness of modification and the degree of coverage of the inorganic support with the applied modifiers were estimated on the basis of elemental analysis and Xray photoelectron spectroscopy (XPS). The content of carbon, hydrogen, oxygen, fluorine, silicon, and magnesium in the structure of the samples was determined. Percentage contributions of the above-mentioned elements are given in Tables 3 and 4. According to the data collected, the content of fluorine on the surface of both fillers (silica and magnesium silicate) increases with increasing quantity of alkylsilane applied in the process of modification. The quantity of fluorine in the silica sample modified with 10 weight parts by mass of OPF was $23.10 \%$ atm., while in the magnesium silicate sample modified with the same amount of the same modifier it was $8.07 \% \mathrm{~atm}$. An increasing amount of modifier also caused an increase in the content of carbon, from $1.72 \%$ for unmodified silica to $6.27 \%$ for silica modified with 10 weight parts by mass of ODS and from $0.00 \%$ to $3.59 \%$ for unmodified and ODS-grafted magnesium silicate, respectively. The degree of coverage of the support surface with selected modifier also increases with increasing amount of silane used, reaching a maximum value of $7.61 \mu \mathrm{mol} / \mathrm{m}^{2}$ for 
TABLE 3: Chemical composition and degree of coverage of both unmodified and grafted silica.

\begin{tabular}{|c|c|c|c|c|c|c|}
\hline \multirow{3}{*}{ Sample } & \multicolumn{5}{|c|}{ Content } & \multirow{3}{*}{ Degree of coverage $\left(\mu \mathrm{mol} / \mathrm{m}^{2}\right)$} \\
\hline & \multicolumn{2}{|c|}{ Elemental analysis } & \multicolumn{3}{|c|}{ XPS } & \\
\hline & $\mathrm{C}(\%)$ & $\mathrm{H}(\%)$ & $\mathrm{O}(\%$ atm. $)$ & $\mathrm{F}(\%$ atm. $)$ & $\mathrm{Si}(\%$ atm.) & \\
\hline $\mathrm{SiO}_{2}$ & 1.72 & 1.46 & 54.21 & - & 24.98 & - \\
\hline $\mathrm{SiO}_{2}+3$ wt./wt. of OPF & 2.17 & 1.57 & 48.51 & 11.12 & 22.91 & 4.53 \\
\hline $\mathrm{SiO}_{2}+5$ wt./wt. of OPF & 2.57 & 1.67 & 42.97 & 17.85 & 19.64 & 5.24 \\
\hline $\mathrm{SiO}_{2}+10$ wt./wt. of OPF & 3.27 & 1.67 & 39.25 & 23.10 & 18.81 & 7.61 \\
\hline $\mathrm{SiO}_{2}+3$ wt./wt. of ODS & 2.80 & 1.54 & 38.98 & \multirow{6}{*}{ Not determined } & 19.87 & 3.74 \\
\hline $\mathrm{SiO}_{2}+5$ wt./wt. of ODS & 4.30 & 1.85 & 42.83 & & 21.59 & 4.14 \\
\hline $\mathrm{SiO}_{2}+10$ wt./wt. of ODS & 6.27 & 2.36 & 45.79 & & 24.65 & 4.78 \\
\hline $\mathrm{SiO}_{2}+3$ wt./wt. of OCS & 2.25 & 1.87 & 48.78 & & 22.68 & 4.48 \\
\hline $\mathrm{SiO}_{2}+5$ wt./wt. of OCS & 2.59 & 1.98 & 50.57 & & 24.82 & 4.65 \\
\hline $\mathrm{SiO}_{2}+10$ wt./wt. of OCS & 3.08 & 2.00 & 53.78 & & 27.98 & 5.20 \\
\hline
\end{tabular}

TABLE 4: Chemical composition and degree of coverage of both unmodified and grafted magnesium silicate.

\begin{tabular}{|c|c|c|c|c|c|c|c|}
\hline \multicolumn{8}{|c|}{ Content } \\
\hline \multirow[t]{2}{*}{ Sample } & \multicolumn{2}{|c|}{ Elemental analysis } & \multicolumn{4}{|c|}{ XPS } & \multirow{2}{*}{ Degree of coverage $\left(\mu \mathrm{mol} / \mathrm{m}^{2}\right)$} \\
\hline & $\mathrm{C}(\%)$ & $\mathrm{H}(\%)$ & $\mathrm{O}(\%$ atm.) & $\mathrm{F}(\%$ atm. $)$ & $\mathrm{Si}(\%$ atm.) & $\operatorname{Mg}(\%$ atm.) & \\
\hline $\mathrm{MgO} \cdot \mathrm{SiO}_{2}$ & - & 3.03 & 63.29 & - & 21.90 & 8.00 & - \\
\hline $\mathrm{MgO} \cdot \mathrm{SiO}_{2}+3$ wt./wt. of OPF & 1.57 & 2.78 & 59.88 & 3.12 & 19.67 & 7.09 & 0.21 \\
\hline $\mathrm{MgO} \cdot \mathrm{SiO}_{2}+5$ wt./wt. of OPF & 1.95 & 2.86 & 57.82 & 4.51 & 17.35 & 7.42 & 0.25 \\
\hline $\mathrm{MgO} \cdot \mathrm{SiO}_{2}+10$ wt./wt. of OPF & 2.29 & 2.98 & 50.34 & 8.07 & 19.31 & 7.21 & 0.30 \\
\hline $\mathrm{MgO} \cdot \mathrm{SiO}_{2}+3$ wt./wt. of ODS & 1.90 & 3.06 & 56.78 & \multirow{6}{*}{ Not determined } & 19.10 & 7.11 & 0.17 \\
\hline $\mathrm{MgO} \cdot \mathrm{SiO}_{2}+5$ wt./wt. of ODS & 2.14 & 3.13 & 58.35 & & 20.50 & 7.71 & 0.17 \\
\hline $\mathrm{MgO} \cdot \mathrm{SiO}_{2}+10$ wt./wt. of ODS & 3.59 & 3.29 & 59.98 & & 22.05 & 7.99 & 0.21 \\
\hline $\mathrm{MgO} \cdot \mathrm{SiO}_{2}+3$ wt./wt. of OCS & 1.02 & 2.46 & 59.78 & & 19.87 & 7.10 & 0.20 \\
\hline $\mathrm{MgO} \cdot \mathrm{SiO}_{2}+5$ wt./wt. of OCS & 1.25 & 2.73 & 62.10 & & 21.33 & 8.45 & 0.22 \\
\hline $\mathrm{MgO} \cdot \mathrm{SiO}_{2}+10$ wt./wt. of OCS & 1.58 & 2.97 & 65.34 & & 24.56 & 9.98 & 0.26 \\
\hline
\end{tabular}

silica modified with 10 weight parts by mass OPF, while for magnesium silicate modified with the same alkylsilane in the same amount the degree of coverage is $0.30 \mu \mathrm{mol} / \mathrm{m}^{2}$.

To verify the possibility of using the silicas and magnesium silicate as adsorbents and polymer fillers, their parameters of porous structure were characterized, based on BET equation as well as nitrogen adsorption/desorption isotherms. Table 5 presents the parameters of porous structure of functionalized silica and silicate fillers. Irrespective of the modifier used, a decrease in the values for the surface area of functionalized hybrid fillers was observed, which indirectly testifies to the effectiveness of modification process. For silica-based fillers the highest value of surface area was found for unmodified silica $\left(48 \mathrm{~m}^{2} / \mathrm{g}\right)$, and the lowest one $\left(17 \mathrm{~m}^{2} / \mathrm{g}\right)$ for silica modified with 10 weight parts by mass of ODS. The surface area of unmodified magnesium silicate is $480 \mathrm{~m}^{2} / \mathrm{g}$, which is much higher than that obtained for the hydrophobized samples. In turn, the lowest surface area of $310 \mathrm{~m}^{2} / \mathrm{g}$ was obtained for the sample of $\mathrm{MgO} \cdot \mathrm{SiO}_{2}$ functionalized with 10 weight parts by mass of OCS.

Besides the introduction of functional groups, the functionalization process is also intended to enhance the hydrophobicity of the samples relative to that of the raw silica or magnesium silicate. The hydrophilic/hydrophobic properties of the samples were evaluated on the basis of wettability profiles (Figure 8). Analysing the experimental data, an increase in the hydrophobicity of the modified samples was noted. The smallest mass increase, and thus the weakest affinity to water, was established for the silica and magnesium silicate samples modified with 5 weight parts by mass of OPF (Figures 8(a) and 8(b)).

Many previously published papers have been focused on the silane-functionalization of inorganic fillers, but the novelty of the present work is the application of newly synthesized fluorosilane for this purpose. Using this silane for modification of fillers will probably extend the range of their functionality and utility.

\section{Conclusions}

Modification of silica and magnesium silicate carried out with 3-(2,2,3,3,4,4,5,5-octafluoropentyloxy)propyltriethoxysilane (OPF), octadecylsilane (ODS), or octyltriethoxysilane (OCS), used in amounts of 3, 5, and 10 weight parts by mass, 


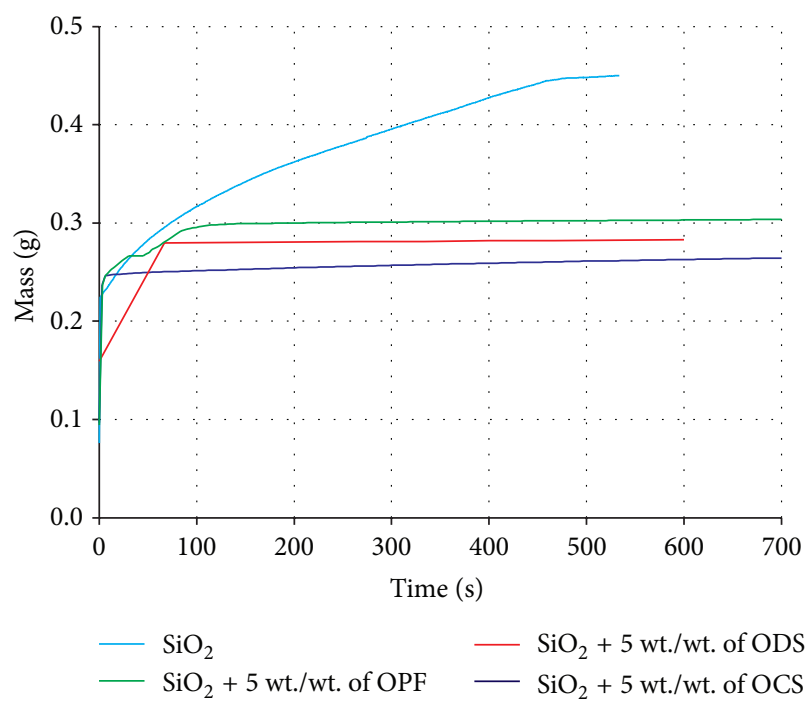

(a)

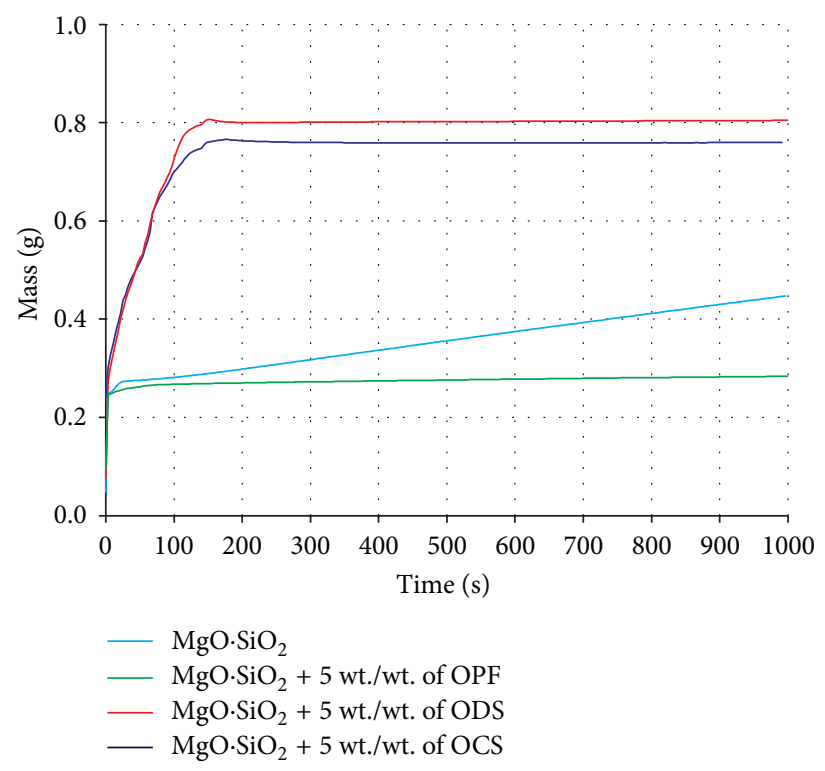

(b)

FIGURE 8: Wettability profiles of (a) silica- and (b) magnesium silicate-based fillers.

TABLE 5: Parameters of porous structure of the obtained fillers.

\begin{tabular}{|c|c|c|c|}
\hline Filler type & $\begin{array}{l}\text { Modifying } \\
\text { agent type }\end{array}$ & $\begin{array}{l}\text { Amount of } \\
\text { modifying agent } \\
\text { (wt./wt.) }\end{array}$ & $A_{\mathrm{BET}}\left(\mathrm{m}^{2} / \mathrm{g}\right)$ \\
\hline \multirow{10}{*}{$\mathrm{SiO}_{2}$} & - & - & 48 \\
\hline & & 3 & 32 \\
\hline & OPF & 5 & 31 \\
\hline & & 10 & 28 \\
\hline & & 3 & 37 \\
\hline & ODS & 5 & 22 \\
\hline & & 10 & 17 \\
\hline & & 3 & 38 \\
\hline & OCS & 5 & 37 \\
\hline & & 10 & 24 \\
\hline \multirow{10}{*}{$\mathrm{MgO} \cdot \mathrm{SiO}_{2}$} & - & - & 480 \\
\hline & & 3 & 471 \\
\hline & OPF & 5 & 367 \\
\hline & & 10 & 362 \\
\hline & & 3 & 392 \\
\hline & ODS & 5 & 369 \\
\hline & & 10 & 341 \\
\hline & & 3 & 360 \\
\hline & OCS & 5 & 324 \\
\hline & & 10 & 310 \\
\hline
\end{tabular}

resulted in increased hydrophobicity of the hybrid fillers and pronounced agglomeration of the products' particles. The products with optimal physicochemical parameters (relatively high homogeneity and hydrophobicity) proved to be those modified with 3 - $(2,2,3,3,4,4,5,5$-octafluoropentyloxy)propyltriethoxysilane. Based on electrokinetic properties evaluation, it was confirmed that this kind of oxide systems is characterized by high electrokinetic stability, especially in alkaline $\mathrm{pH}$ range. Moreover, functionalization of oxides surface with selected silanes (especially with OPF) significantly affect the measured values of the zeta potential and the electrokinetic stability.

Performed FTIR and XPS spectral investigations as well as elemental analysis results proved the chemical nature of interactions and the effectiveness of the modification process.

Surface modification of silica-based fillers with 3(2,2,3,3,4,4,5,5-octafluoropentyloxy)propyltriethoxysilane caused the smallest decrease in the surface area, even when used in the amount of 10 weight parts by mass. Due to obtained results, it is expected that inorganic powders modified with OPF will be successfully applied as functional fillers in selected polymer composites, as an alternative for commonly used silanes.

\section{Acknowledgments}

This work was supported by the following research grants: Poznan University of Technology (32-375/2013-DS) and Ministry of Science and Higher Education (N N209 765640).

\section{References}

[1] M. W. Daniels and L. F. Francis, "Silane adsorption behavior, microstructure, and properties of glycidoxypropyltrimethoxysilane-modified colloidal silica coatings," Journal of Colloid and Interface Science, vol. 1, no. 1, pp. 191-200, 1998.

[2] C. Gellermann, W. Storch, and H. Wolter, "Synthesis and characterization of the organic surface modifications of monodisperse colloidal silica," Journal of Sol-Gel Science and Technology, vol. 8, no. 1-3, pp. 173-176, 1997.

[3] V. M. Sglavo, S. Diré, and M. Ferrari, "Structure-property behavior during aging of sol-gel-derived silica modified with 
$\mathrm{Si}-\mathrm{H}$ and $\mathrm{Si}-\mathrm{CH}_{3}$ groups," Journal of Materials Research, vol. 14, no. 5, pp. 2100-2106, 1999.

[4] H. Zhang and C. G. Pantano, "Synthesis and characterization of silicon oxycarbide glasses," Journal of the American Ceramic Society, vol. 73, no. 4, pp. 958-963, 1990.

[5] N. Nishiyama, R. Shick, and H. Ishida, "Adsorption behavior of a silane coupling agent on colloidal silica studied by gel permeation chromatography," Journal of Colloid and Interface Science, vol. 143, no. 1, pp. 146-156, 1991.

[6] J. P. Blitz, R. S. S. Murthy, and D. E. Leyden, "Studies of silylation of Cab-O-Sil with methoxymethylsilanes by diffuse reflectance FTIR spectroscopy," Journal of Colloid and Interface Science, vol. 121, no. 1, pp. 63-69, 1988.

[7] J. P. Blitz, R. S. S. Murthy, and D. E. Leyden, "The role of amine structure on catalytic activity for silylation reactions with CabO-Sil," Journal of Colloid and Interface Science, vol. 126, no. 2, pp. 387-392, 1988.

[8] J. P. Blitz, R. S. S. Murthy, and D. E. Leyden, "Ammoniacatalyzed silylation reactions of Cab-O-Sil with methoxymethylsilanes," Journal of the American Chemical Society, vol. 109, no. 23, pp. 7141-7145, 1987.

[9] K. M. R. Kallury, P. M. Macdonald, and M. Thompson, "Effect of surface water and base catalysis on the silanization of silica by (aminopropyl)alkoxysilanes studied by X-ray photoelectron spectroscopy and ${ }^{13} \mathrm{C}$ cross-polarization/magic angle spinning nuclear magnetic resonance," Langmuir, vol. 10, no. 2, pp. 492499, 1994.

[10] M. E. McGovern, K. M. R. Kallury, and M. Thompson, "Role of solvent on the silanization of glass with octadecyltrichlorosilane," Langmuir, vol. 10, no. 2, pp. 3607-3614, 1994.

[11] R. Maoz and J. Sagiv, "On the formation and structure of selfassembling monolayers. I. A comparative atr-wettability study of Langmuir-Blodgett and adsorbed films on flat substrates and glass microbeads," Journal of Colloid and Interface Science, vol. 100, no. 2, pp. 465-496, 1984.

[12] D. A. Offord and J. H. Griffin, "Kinetic control in the formation of self-assembled mixed monolayers on planar silica substrates," Langmuir, vol. 9, no. 11, pp. 3015-3025, 1993.

[13] J. D. Le Grange, J. L. Markham, and C. R. Kurkjian, "Effects of surface hydration on the deposition of silane monolayers on silica," Langmuir, vol. 9, no. 11, pp. 1749-1753, 1993.

[14] J. E. Sandoval and J. J. Pesek, "Synthesis and characterization of a hydride-modified porous silica material as an intermediate in the preparation of chemically bonded chromatographic stationary phases," Analytical Chemistry, vol. 61, no. 18, pp. 2067-2075, 1989.

[15] J. J. Pesek, J. E. Sandoval, and M. Su, "New alumina-based stationary phases for high-performance liquid chromatography. Synthesis by olefin hydrosilation on a silicon hydride-modified alumina intermediate," Journal of Chromatography, vol. 630, no. 1-2, pp. 95-103, 1993.

[16] C. Chu, E. Jonsson, M. Auvinen, J. J. Pesek, and J. E. Sandoval, "A new approach for the preparation of a hydride-modified substrate used as an intermediate in the synthesis of surfacebonded materials," Analytical Chemistry, vol. 65, no. 6, pp. 808816, 1993.

[17] J. B. Danner and J. M. Vohs, "The chemistry of organosilane/metal oxide interfaces: reaction of trimethoxysilane on $\mathrm{MgO}$ and $\mathrm{SiO}_{2}$ surfaces," Applied Surface Science, vol. 62, no. 4, pp. 255-262, 1992.

[18] D. W. Sindorf and G. E. Maciel, "Cross-polarization/magicangle-spinning silicon-29 nuclear magnetic resonance study of silica gel using trimethylsilane bonding as a probe of surface geometry and reactivity," Journal of Physical Chemistry, vol. 86, no. 26 , pp. 5208-5219, 1982.

[19] D. G. Kurth and T. Bein, "Monomolecular layers and thin films of silane coupling agents by vapor-phase adsorption on oxidized aluminum," Journal of Physical Chemistry, vol. 96, no. 16, pp. 6707-6712, 1992.

[20] V. A. Basyuk, "Reactions of gaseous organic compounds on silica surface. Spectral studies and synthetic aspects," Reaction Kinetics \& Catalysis Letters, vol. 50, no. 1-2, pp. 83-88, 1993.

[21] K. L. Mittal, Silane and other Coupling Agents, VSP, Utrecht, The Netherlands, 1992.

[22] T. Jesionowski and A. Krysztafkiewicz, "Comparison of the techniques used to modify amorphous hydrated silicas," Journal of Non-Crystalline Solids, vol. 277, no. 1, pp. 45-57, 2000.

[23] E. P. Pluddemann, Silane Coupling Agents, Academic Press, New York, NY, USA, 1982.

[24] A. Krysztafkiewicz, B. Rager, and T. Jesionowski, “The effect of surface modification on physicochemical properties of precipitated silica," Journal of Materials Science, vol. 32, no. 5, pp. 13331339, 1997.

[25] L. Sierra, B. Lopez, and J. Guth, "Preparation of mesoporous silica particles with controlled morphology from sodium silicate solutions and a non-ionic surfactant at $\mathrm{pH}$ values between 2 and 6," Microporous and Mesoporous Materials, vol. 39, no. 3, pp. 519-527, 2000.

[26] T. Suhara, H. Fukui, and M. Yamaguchi, "Fine silica powder modified with quaternary ammonium groups 2 . The influence of electrolyte and pH," Colloids and Surfaces A, vol. 101, no. 1, pp. 29-37, 1995.

[27] T. Suhara, H. Fukui, M. Yamaguchi, and F. Suzuki, "Fine silica powder modified with quaternary ammonium group. 3 . the adsorption behavior of anionic surfactants," Colloids and Surfaces A, vol. 119, no. 1-2, pp. 15-21, 1996.

[28] T. Suhara, F. Shimano, Y. Sato, H. Fukui, and M. Yamaguchi, "Fine silica powder modified with quaternary ammonium group 4. Bactericidal activity," Colloids and Surfaces A, vol. 119, no. 2-3, pp. 105-114, 1996.

[29] J. Zajac, "Adsorption microcalorimetry used to study interfacial aggregation of quaternary ammonium surfactants (zwitterionic and cationic) on powdered silica supports in dilute aqueous solutions," Colloids and Surfaces A, vol. 167, no. 1-2, pp. 3-19, 2000.

[30] M. Drach, Ł. Łajtar, J. Narkiewicz-Michałek, W. Rudziński, and J. Zając, "Adsorption of cationic surfactants on hydrophobic silica: effect of surface energetic heterogeneity," Colloids and Surfaces A, vol. 145, no. 1-3, pp. 243-261, 1998.

[31] I. Rachas, T. F. Tadros, and P. Taylor, "The displacement of adsorbed polymer from silica surfaces by the addition of a nonionic surfactant," Colloids and Surfaces A, vol. 161, no. 2, pp. 307-319, 2000.

[32] S. Lagerge, E. Keh, S. Partyka, and M. Lindheimer, "On the behavior of nonionic surfactants at the N-heptane/silica gel interface: Influence of the presence of interfacial water inferred from adsorption isotherms and galorimetric data," Journal of Colloid and Interface Science, vol. 227, no. 2, pp. 412-420, 2000.

[33] Y. Cheng, H. Lin, and C. Mou, "Control of mesostructure and morphology of surfactant-templated silica in a mixed surfactant system," Physical Chemistry Chemical Physics, vol. 1, no. 21, pp. 5051-5058, 1999. 
[34] A. Y. Fadeev and Y. V. Kazakevich, "Covalently attached monolayers of oligo(dimethylsiloxane)s on silica: a siloxane chemistry approach for surface modification," Langmuir, vol. 18, no. 7, pp. 2665-2672, 2002.

[35] T. I. Suratwala, M. L. Hanna, E. L. Miller et al., "Surface chemistry and trimethylsilyl functionalization of Stöber silica sols," Journal of Non-Crystalline Solids, vol. 316, no. 2-3, pp. 349363, 2003.

[36] M. C. Capel-Sanchez, L. Barrio, J. M. Campos-Martin, and J. L. G. Fierro, "Silylation and surface properties of chemically grafted hydrophobic silica," Journal of Colloid and Interface Science, vol. 277, no. 1, pp. 146-153, 2004.

[37] E. Loste, J. Fraile, M. A. Fanovich, G. F. Woerlee, and C. Domingo, "Anhydrous supercritical carbon dioxide method for the controlled silanization of inorganic nanoparticles," Advanced Materials, vol. 16, no. 8, pp. 739-744, 2004.

[38] N. Ardès-Guisot, J. Durand, M. Granier et al., "Trichlorosilane isocyanate as coupling agent for mild conditions functionalization of silica-coated surfaces," Langmuir, vol. 21, no. 21, pp. 9406-9408, 2005.

[39] H. Maciejewski, B. Marciniec, I. Dąbek, and J. Karasiewicz, Polish patent application P-388 929.

[40] T. G. Waddell, D. E. Leyden, and M. T. DeBello, "The nature of organosilane to silica-surface bonding," Journal of the American Chemical Society, vol. 103, no. 18, pp. 5303-5307, 1981.

[41] X. Liu, Z. Ma, J. Xing, and H. Liu, "Preparation and characterization of amino-silane modified superparamagnetic silica nanospheres," Journal of Magnetism and Magnetic Materials, vol. 270, no. 1-2, pp. 1-6, 2004.

[42] B. I. Lee and U. Paik, "Effect of aminosilane adsorption on rheology of silica powders in nonaqueous media," Journal of Materials Science, vol. 27, no. 21, pp. 5692-5700, 1992.

[43] R. S. McDonald, "Surface functionality of amorphous silica by infrared spectroscopy," Journal of Physical Chemistry, vol. 62, no. 10, pp. 1168-1178, 1958.

[44] R. Al-Oweini and H. El-Rassy, "Synthesis and characterization by FTIR spectroscopy of silica aerogels prepared using several $\mathrm{Si}(\mathrm{OR})_{4}$ and $\mathrm{R}^{\prime \prime} \mathrm{Si}\left(\mathrm{OR}^{\prime}\right)_{3}$ precursors," Journal of Molecular Structure, vol. 919, no. 1-3, pp. 140-145, 2009.

[45] R. Brambilla, G. P. Pires, J. H. Z. dos Santos, M. S. L. Miranda, and B. Chornik, "Octadecylsilane-modified silicas prepared by grafting and sol-gel methods," Journal of Electron Spectroscopy and Related Phenomena, vol. 156-158, pp. 413-420, 2007.

[46] T. Jesionowski, M. Nowacka, and F. Ciesielczyk, "Electrokinetic properties of hybrid pigments obtained via adsorption of organic dyes on the silica support," Pigment and Resin Technology, vol. 41, no. 1, pp. 9-19, 2012.

[47] V. C. Farmer, "The layer silicates," in The Infrared Spectra of Minerals, Mineralogical Society Monograph, London, UK, 1974.

[48] J. D. Russel, "Infrared methods", in A Handbook of Determinative Methods in Clay Mineralogy, M. J. Wilson, Ed., Blackie Academic and Professional, London, UK, 1987. 

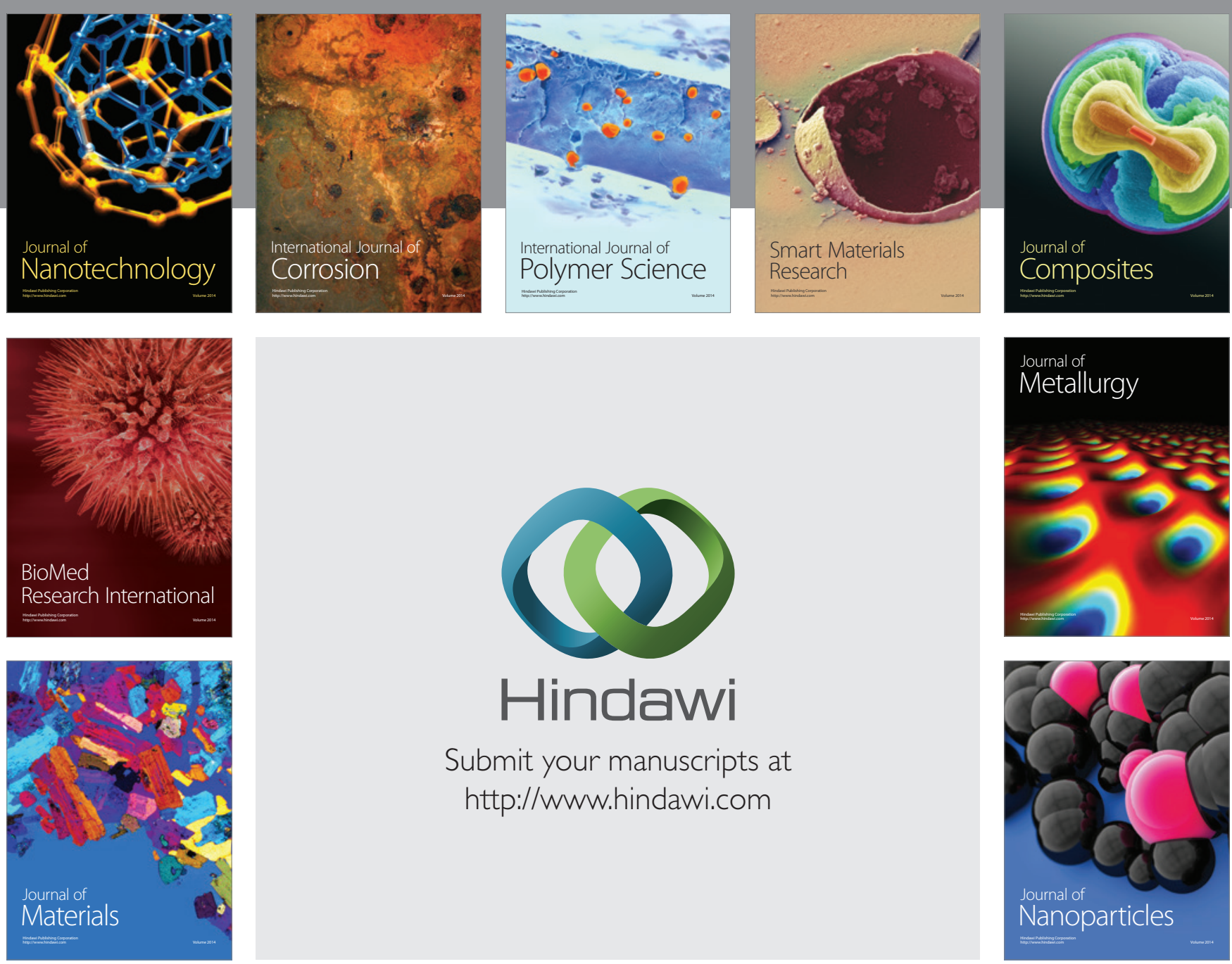

Submit your manuscripts at http://www.hindawi.com
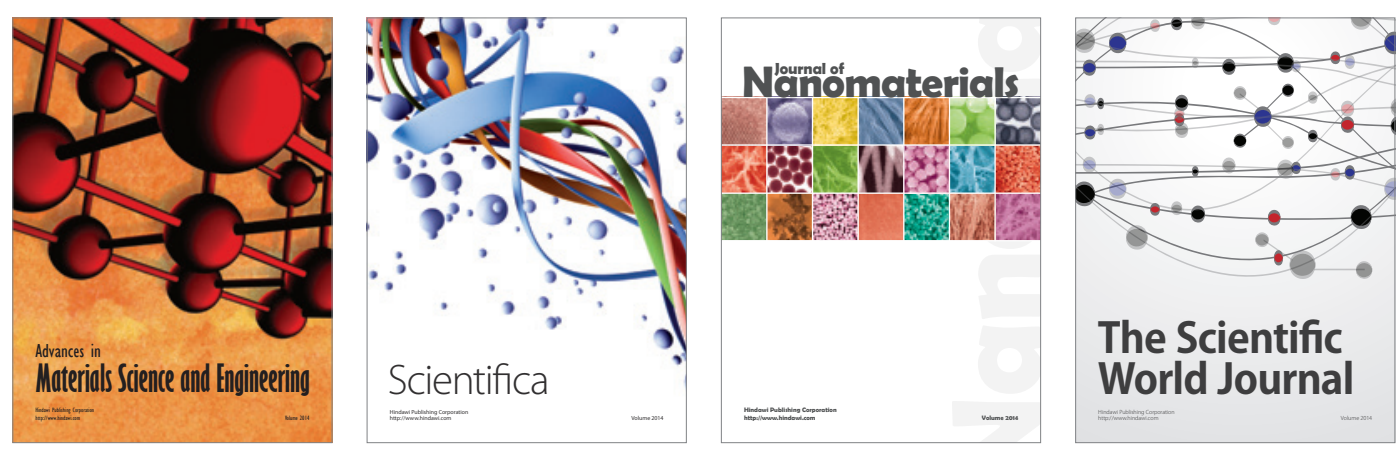

\section{The Scientific World Journal}
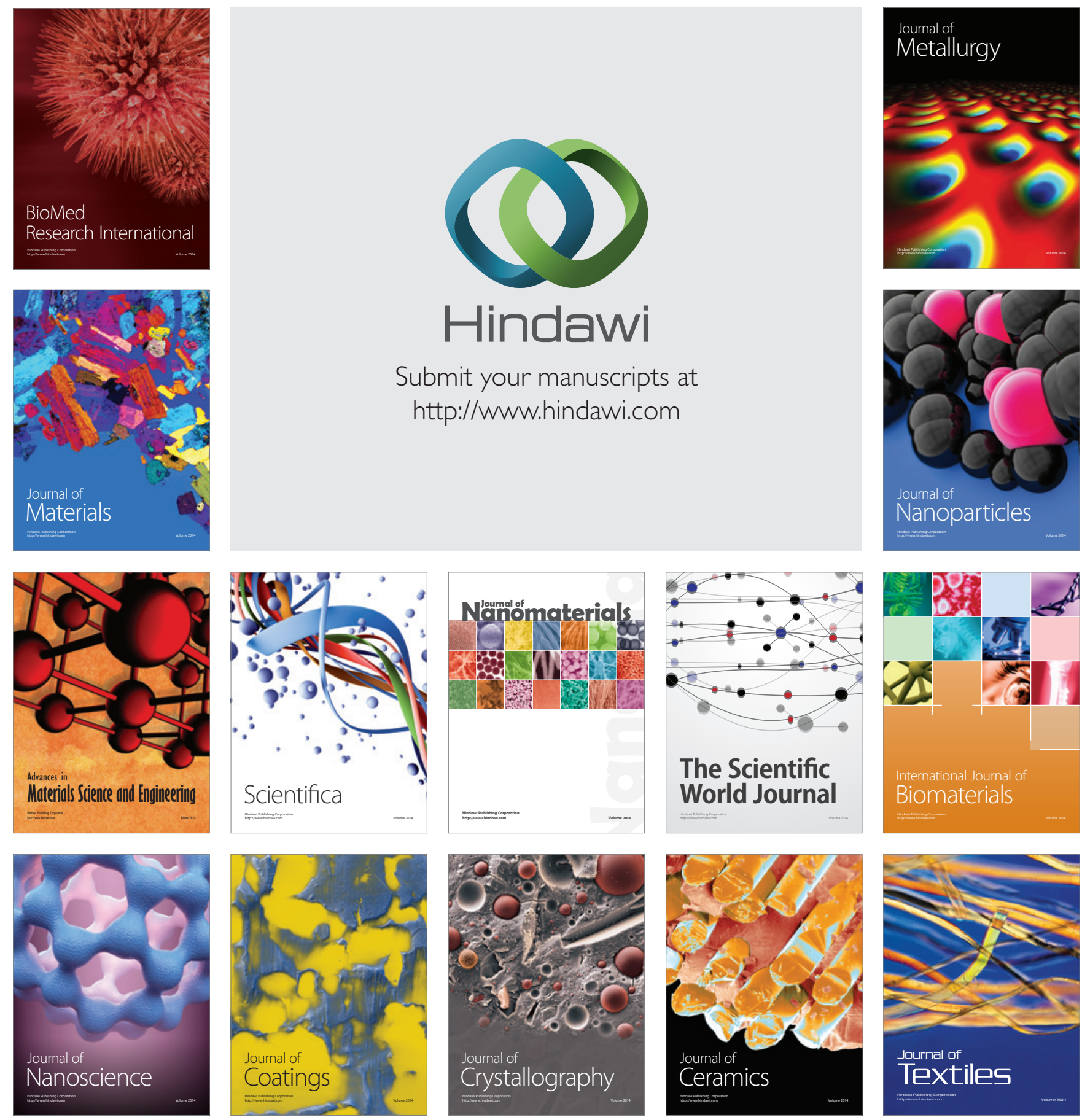